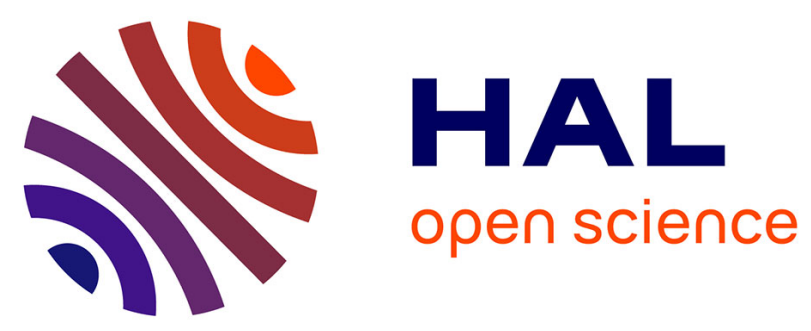

\title{
There and Back Again - Andrew Booth, a British Computer Pioneer, and his Interactions with US and Other Contemporaries
}

Roger G. Johnson

\section{- To cite this version:}

Roger G. Johnson. There and Back Again - Andrew Booth, a British Computer Pioneer, and his Interactions with US and Other Contemporaries. IFIP International Conference on the History of Computing (HC), May 2016, Brooklyn, NY, United States. pp.58-70, 10.1007/978-3-319-49463-0_4 . hal-01620144

\section{HAL Id: hal-01620144 \\ https://hal.inria.fr/hal-01620144}

Submitted on 20 Oct 2017

HAL is a multi-disciplinary open access archive for the deposit and dissemination of scientific research documents, whether they are published or not. The documents may come from teaching and research institutions in France or abroad, or from public or private research centers.
L'archive ouverte pluridisciplinaire HAL, est destinée au dépôt et à la diffusion de documents scientifiques de niveau recherche, publiés ou non, émanant des établissements d'enseignement et de recherche français ou étrangers, des laboratoires publics ou privés. 


\title{
There and Back Again - Andrew Booth, a British Computer Pioneer, and his Interactions with US and other Contemporaries
}

\author{
Roger G Johnson \\ School of Computer Science, Birkbeck College, London University, UK \\ (rgjedcs.bbk.ac.uk)
}

\begin{abstract}
This paper explores the interchanges between Andrew Booth, an early British computer pioneer and contemporary US and other pioneers. The paper records how funding from the US Rockefeller Foundation supported Andrew Booth's research work in the UK and allowed him to refine his ideas on computer design by visiting US pioneers each year from 1946 to 1948 . This led to the construction of an electronic drum, the world's first successful demonstration of a rotating storage device connected to a computer, to his pioneering work on natural language processing and finally and most notably to his invention of the Booth hardware multiplier which is the basis of the multiplier used in billions of chips each year.
\end{abstract}

Keywords Andrew Booth, APERC, HEC, magnetic drum, Booth multiplier, British Tabulating Machine Ltd

\section{Background}

The story starts slightly improbably in the world of the crystal structure of explosives. In the closing days of World War II, the leading British scientist, J D (Desmond) Bernal was planning his return from war service to the quieter world of academia. He held the Chair of Physics at Birkbeck College, London University and decided to form a group of academics to examine the structure of crystals using X-rays, work which contributed in the 1950s to the discovery of the double helix. This involved solving large sets of equations which, before computers, had to be done largely by hand using mostly simple electro-mechanical calculators and it took weeks to complete just one set of calculations.

Bernal decided that one of the four groups in his new department would be devoted to the mechanisation of these calculations. His attention was drawn by Douglas Hartree, then a mathematics professor at Manchester and builder of a large differential analyser before the war, to a talented young man, Andrew Donald Booth (born Feb $11^{\text {th }} 1918$ and died Nov $29^{\text {th }} 2009$ ), who had a PhD on the crystal structure of explosives and an enthusiasm for mechanising the calculations. In 1975, in an interview with Christopher Evans for the London Science Museum, [1], Booth related 
how during the war he managed a small team of women doing calculations derived from x-rays of crystal structures and

being by temperament a mathematician I don't like arithmetic. .... I didn't think much of the methods they were using and I tried to do two things. In the first place I devised some better mathematical methods ... but I also made one or two small hand calculators.

Joining Birkbeck in late 1945 to head Bernal's new group on mechanising the calculations, Booth proved an excellent choice combining a first class mathematical mind capable of working on the complexities needed to handle the mathematics of Xray crystallography to obtain but most importantly for computing, he was described by those who later worked with him as a "natural engineer". His engineering skills were perhaps derived from his father who was a retired marine engineer and part time inventor.

He was then working on a mechanical Fourier synthesizer, [2]. However, at an early stage he incorporated relays into the device and named it the Automatic Relay Calculator (ARC). Due to a lack of space at Birkbeck, which had been badly damaged by bombing in 1941, the calculator was built at the British Rubber Producers Research Association (BRPRA) in Welwyn Garden City who sponsored the project and where Booth had worked briefly before joining Birkbeck.

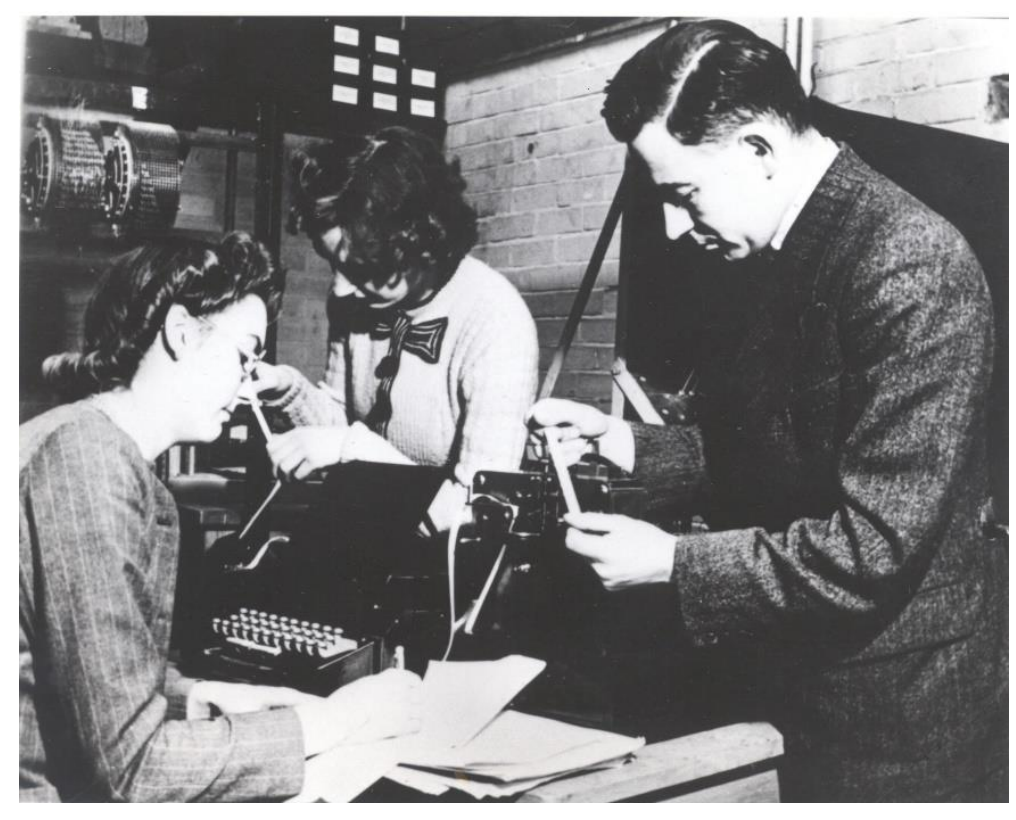

Fig. 1. Andrew Booth and Kathleen Britten (in the foreground) at work in December 1945 


\section{First Visit to the USA 1946}

Hartree had visited a number of US computing projects in 1945 and was aware of the EDVAC project. On his return to the UK he shared his observations with the nascent UK computing community, including both Wilkes at Cambridge and Booth at Birkbeck. Hartree suggested to Bernal that, in view of the lack of funding available in the UK, a grant should be sought from the Rockefeller Foundation (RF) in the USA (from whom Bernal had already received several grants) to allow Booth to make a short visit to the USA starting in May 1946 to attend the conference of the American Society for X-Ray and Electron Diffraction and visit a number of crystallographic and computing projects.

The RF archives reveal that Booth made a very good impression on Warren Weaver, Director of the RF's Natural Sciences Division. Weaver's notes of their first meeting on June $20^{\text {th }} 1946$, [3], record

He appears very young (under 25) [he was actually 28] and is most attractive in every way. He seems to be equally interested and competent in the mathematical and instrumental aspects of his subject.

After attending the conference Booth was able to visit a number of researchers along the eastern seaboard. So soon after the end of the war and with much of the research funded by the US government it is unsurprising that Booth felt some of those to whom he talked were rather reticent in their comments. An exception was John von Neumann, although the latter's friendship with Bernal may well have been helpful. In the cover letter, dated July $3^{\text {rd }} 1946$, to his final report Booth, [4], notes that

In addition to purely crystallographic projects I have seen most of the special calculating machines. With the exception of that of $\mathrm{Dr}$ von Neumann, the techniques are well known to me. I had a long discussion with Dr von Neumann and came to the conclusion that a machine built in accordance with some of his ideas would revolutionise crystallographic computing, and would be especially applicable to problems of biological interest. I should very much like to discuss with you the possibility of my spending six months to Princeton and, if possible developing such a machine.

\section{Back in the UK 1946}

Following the end of World War 2, four groups in the UK were looking at building digital computers. The best known were at Manchester (associated with Freddie Williams and Tom Kilburn) and at Cambridge (led by Maurice Wilkes). The third group was at the National Physical Laboratory, Teddington (led by Jim Wilkinson and Ted Newman using a design by Alan Turing).

The fourth group was that of Booth at Birkbeck College, London University. He was working with limited resources, both human and financial, and concentrating, as 
a result, on building smaller machines. He had a radical ambition for that time of building a computer that was cheap enough that each university could own one! This was at a time when the UK's National Physical Laboratory (NPL) ACE computer was being talked of (at least at NPL) as sufficient for the whole of the UK's computational needs!

\section{Second Visit to USA 1947}

Obtaining the funding for a six month US tour in 1947 was difficult due to the continuing severe currency exchange controls in the UK. The basic funding for expenses within the USA was provided by the RF while the University of London paid Booth's fare on the SS Aquitania. Booth chose to base himself at the Institute of Advanced Studies at Princeton with John von Neumann. Booth was accompanied by his research assistant, Kathleen H V Britten, who was soon to become his wife. In order to provide additional funding for the trip, Bernal put Booth in touch with Isidor Fankuchen, an Adjunct Professor of Physics at Brooklyn Polytechnic who organised for Booth to go on the lunch lecture circuit right across the States talking about contemporary life in Britain, [1]. This enabled them to visit all the major centres of research on x-ray crystallography and, more importantly, computing across the whole country.

This visit was transformative for Booth and Britten. It can be difficult for the modern reader to appreciate the challenge faced by the computer pioneers lacking any consensus "blueprint" for the architecture or components of a computer. From their discussions with John von Neumann, they were introduced to what we now regard as the standard architecture of a computer and which is widely known as the "von Neumann" architecture. Inspired by this discussion, on the liner on the return trip, he redesigned ARC to have a von Neumann architecture which he referred to as ARC2. This machine used 800 high-speed relays to form a parallel operation single address code computer.

\section{The Challenge of Memory}

Computer architectures have to be realised using electronics and at that time there was no consensus on the appropriate technology even for fundamental components, such as the computer memory or input and output. Booth and Britten set out the technological options for the components of a computer with a "von Neumann" architecture in a paper which circulated among the growing community of computer pioneers during 1947. Such was the interest, they produced a second edition later that year [5].

The heart of the "von Neumann" architecture is the memory. In their paper the Booths evaluated all of the physical properties including heat, light, sound and magnetism and concluded that magnetism offered the best prospects because of its persistence. 


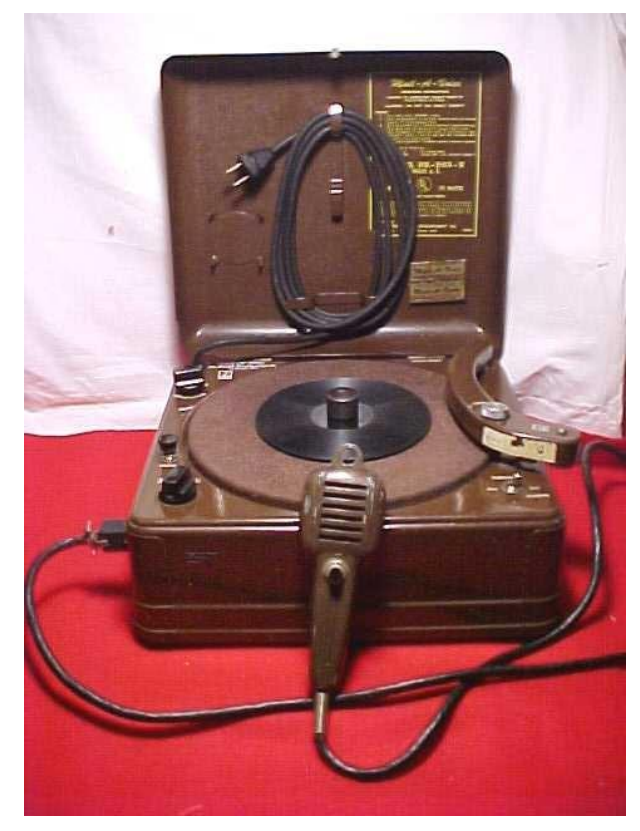

Fig. 2. Brush Mail-a-Voice dictation machine

Booth was committed to building a low cost computer and so he needed low cost components. The two immediate options for a memory were mercury delay lines and CRT display tubes both of which were very costly. On his trip around the USA he had seen a simple recording device, called the Brush Mail-a-Voice, Fig 2, which was sold for use in commercial offices to enable managers to record letters on to magnetic oxide coated paper discs for typing by their secretarial staff. However, in order to achieve the performance needed to act as the memory of a computer he had to rotate the paper disc much faster than for simple voice recording. At this higher speed, it proved impossible to keep the disc flat and so he had to abandon this first attempt at a "floppy disc".

Undaunted he decided to try a different approach and designed a memory using a brass drum with a nickel coating around the outside. The first drum was mounted on a horizontal axle and about the size of a cotton reel, being 2 inches in diameter with a modest packing density of just 10 bits per inch, Fig 3 . 


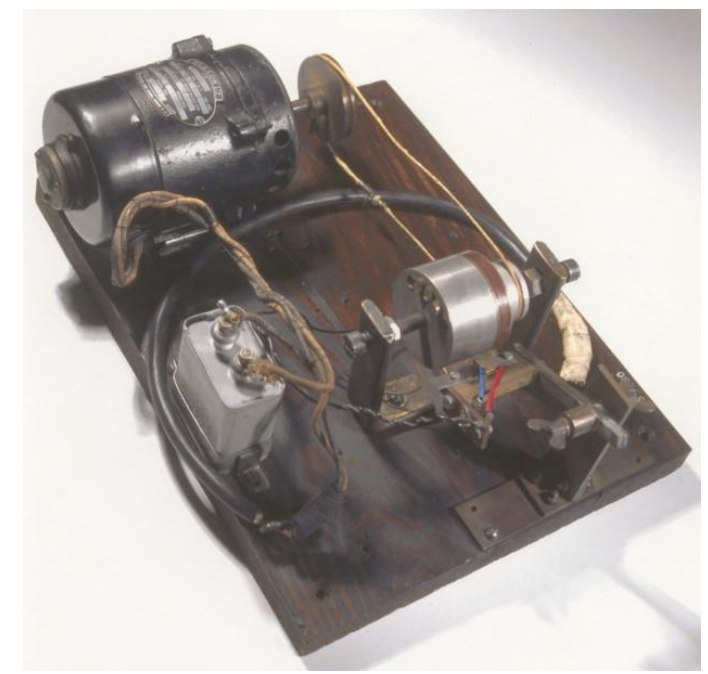

Fig. 3. Booth's first drum Feb 1948 (Photo courtesy of NMSI, London)

Thus it was that Andrew Booth built the world's first rotating electronic storage device connected to a computer albeit a drum rather than the now ubiquitous disc. The drums were built by his father and together they created a company called Wharf Engineering Ltd which manufactured drums and other computer peripherals commercially until the Booths left the UK in 1962. Having proved the drum concept worked, the Booths built a larger nickel-plated brass drum with 256 words of 21 bits to provide the memory for ARC2. It was completed by the end of 1947 and became operational and was still in service at Birkbeck in 1954. The prototype drums are now in the care of the Science Museum, London.

In a paper at a conference on international communities of invention and innovation it is worth noting that Booth gave the design of ARC2 to Adriaan van Wijngarden in Amsterdam for the construction of ARRA, the first computer in the Netherlands.

\section{Building Electronic Computers}

During 1948, Andrew Booth redesigned the ARC2 as an entirely electronic machine which he called the Simple Electronic Computer (SEC). This was built by Norman Kitz (formerly Norbert Kitz) in 1949/50 see Figure 4.

An interesting historical footnote is that Norman Kitz left Birkbeck to work for English Electric at NPL on the DEUCE computer. From there he moved to Bell Punch and designed the world's first electronic desktop calculator, called ANITA. While Booth never completed a desktop calculator, it seems likely that he inspired one of his students to do so. 


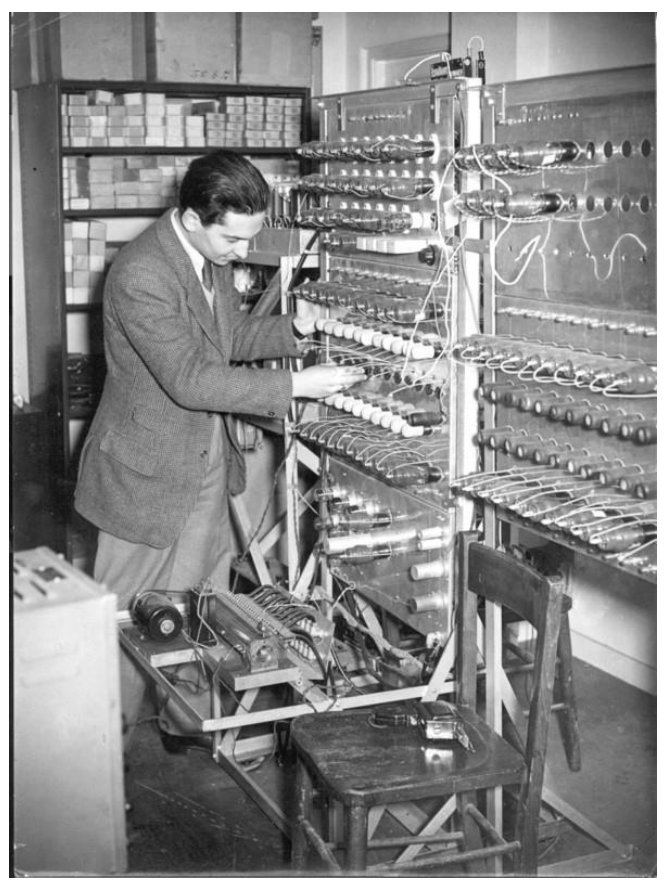

Fig. 4 SEC with Booth's first practical drum in the foreground 1950

SEC used a comparatively small number of 230 valves in its construction and employed a two address set of operation codes. It had a memory of just 256 words of 21 bits. Although Norman Kitz completed its construction the machine never became operational, and using the lessons learnt from SEC, Andrew Booth moved swiftly on to create his best known computer design, the All-Purpose Electronic Computers series of computers, (each identified as $\operatorname{APE}(*) \mathrm{C}$ where the $*$ is the initial letter of the sponsoring body). 


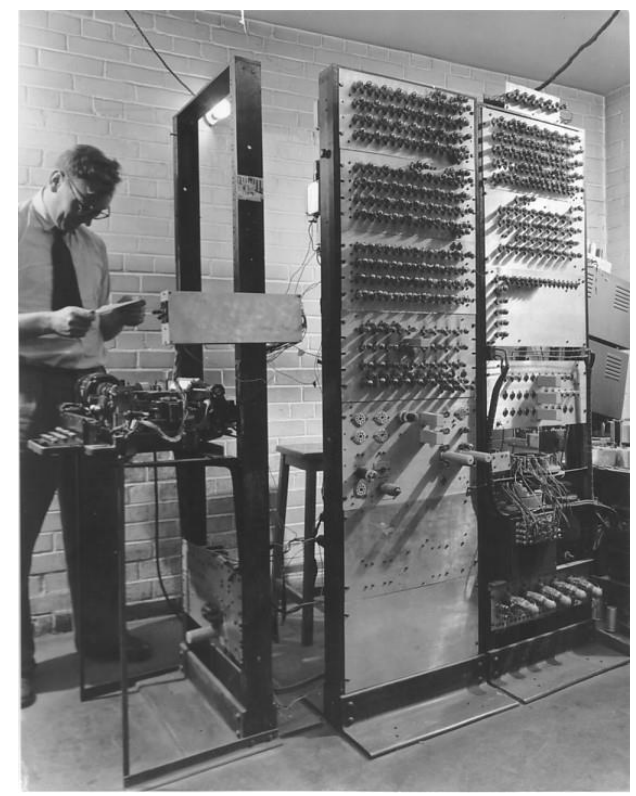

Fig. $5 \mathrm{APE}(\mathrm{R}) \mathrm{C}$ whose circuit designs Booth shared with others 1952

The first machine of the series, known as $\operatorname{APE}(\mathrm{R}) \mathrm{C}$, ran successfully for the first time in May 1952, Fig 5. The (R) signified the British Rayon Research Association for whom it was built. It was constructed at the Booths' home in the small village of Fenny Compton in Warwickshire before being moved to Birkbeck for commissioning and subsequent delivery to the BRRA in Manchester in July 1953. Once the APE(R)C computer was moved to Birkbeck, construction of a larger version, known as $\mathrm{APE}(\mathrm{X}) \mathrm{C}, \mathrm{X}$ for $\mathrm{X}$-ray, for the Birkbeck X-ray crystallographers began in Warwickshire. Both these machines used 500 valves. APE(R)C had a drum with 512 words of 32 bits rotating at 3,000 RPM and ran at $30 \mathrm{KHz}$. By removing some redundant logic, $\mathrm{APE}(\mathrm{X}) \mathrm{C}$ used only 420 valves but ran at $60 \mathrm{KHz}$ and had a much larger drum with over 1,024 words of 32 bits. Input/output on $\mathrm{APE}(\mathrm{X}) \mathrm{C}$ was by either teletype and paper tape.

In 1950 Booth provided the design of $\mathrm{APE}(\mathrm{R}) \mathrm{C}$ to Norwegian researchers led by Thomas Hysing who named their computer NUSSE (Norsk Universell Siffermaskin, Sekvensstyrt, Elektronisk) and was Norway's first electronic computer. This machine is now in the Norwegian Museum of Science and Technology, Oslo, Fig 6. 


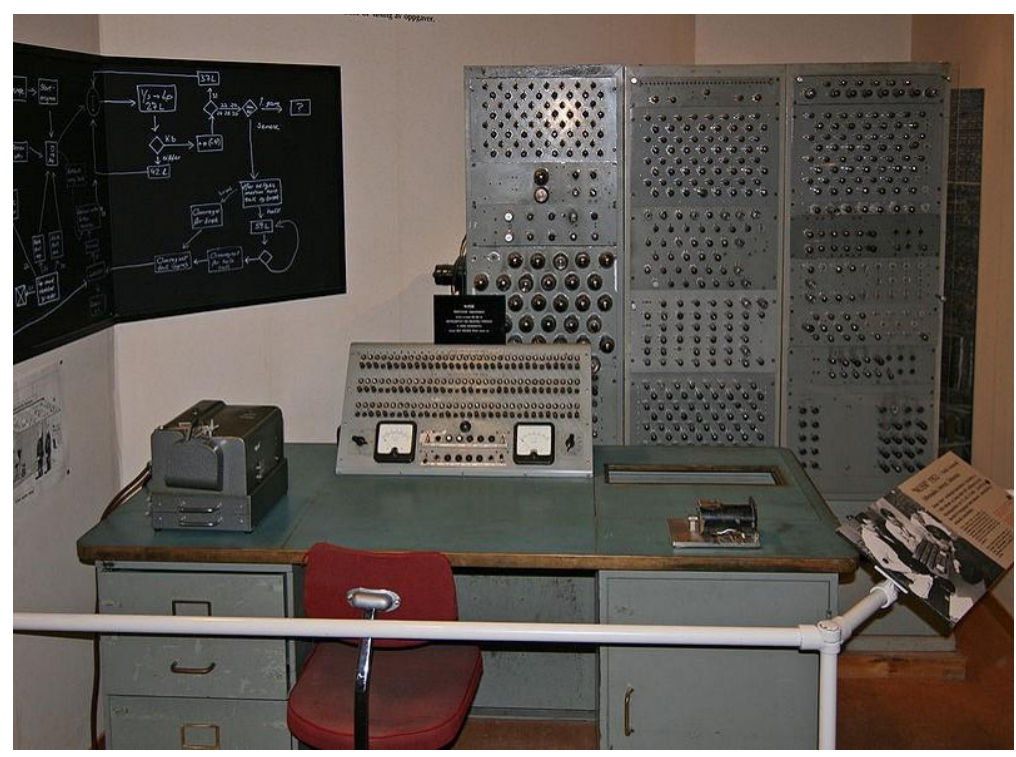

Fig. 6 NUSSE Norway’s first computer derived from Booth's design 1954

\section{Booth Multiplier}

If the drum reflected Booth's engineering talent, then the Booth multiplier was a demonstration of his mathematical skill. A key component of any computer design is the arithmetic unit and to provide fast arithmetic it is necessary to have hardware multiplication and division. When Booth visited von Neumann in 1947 he obtained details of von Neumann's design for both a hardware multiplier and divider. Booth described them in his interview with Evans as "a beautiful divider" but the multiplier as "an abortion" [1]. When Booth asked von Neumann why he had not used a similar approach in his multiplier as in the divider, von Neumann assured him it was a theoretical impossibility and Booth accepted the great man's opinion. Booth told Evans that when he was designing the APEC computer series he realised that von Neumann was wrong and Booth recollected how, over tea with his wife in a central London cafe, he designed a non-restoring binary multiplier which, with a subsequent minor modification by a colleague, is the Booth multiplier which is still in use today.

Basically the Booth multiplier follows the usual method for long multiplication of summing partial products. However, it also uses a "trick" that to multiply in decimal by a string of $9 \mathrm{~s}$ it is possible to left shift an appropriate number of places and subtract the multiplier from the result. This approach works even better in binary where it results in a simple rule for multiplying by a string of $1 \mathrm{~s}$ :

- Examine each pair of digits in the multiplier starting at the least significant digit creating the first pair by appending a dummy 0 at the least significant end of the multiplier, then

i. If the pair is 01, add the multiplicand 
ii. If the pair is 10 , subtract the multiplicand

iii. Otherwise, do nothing

- Shift both the partial product and multiplier one place right and examine the next pair of digits

- Repeat as many times as there are digits in the multiplier.

This was submitted for publication in August 1950 and published the following year [8].

\section{Natural Language Translation}

As quoted above from the covering letter to his final report of the 1946 visit, Booth raised the possibility of the RF funding the construction of a computer in London to support the work of x-ray crystallographers.

On August $11^{\text {th }} 1947$ Booth visited Warren Weaver and asked him if the Foundation would fund an electronic computer for London University. Weaver said that the Foundation could not fund a computer for mathematical calculations which he felt had been done but that he had begun to think about using a computer to carry out natural language translation and that the Foundation could fund a computer for research in that area.

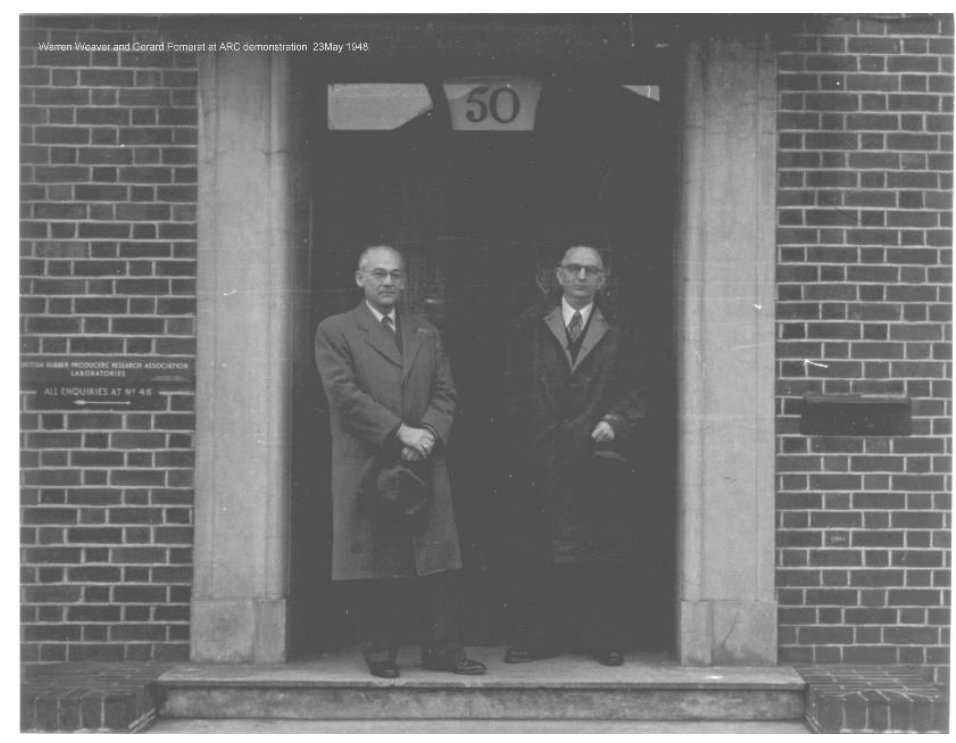

Fig. 7. Warren Weaver and Gerard Pomerat visit ARC May 1948

As a result, Birkbeck became for the next fifteen years a leading centre for natural language processing research. On May $23^{\text {rd }} 1948$ Weaver accompanied by Gerard Pomerat visited Booth's laboratory, Figure 7, still housed in the premises of the British Rubber Producers Research Association at Welwyn Garden City. The tiny 
memory on early computers meant it was very difficult to do any serious natural language processing. Booth gave them a demonstration of the machine, despite a faulty relay! Weaver in his note of the meeting expresses surprise and disappointment that the very small machine simply performs a simple word lookup and that the researchers had not yet considered the problem of a word which has multiple meanings, [6]!

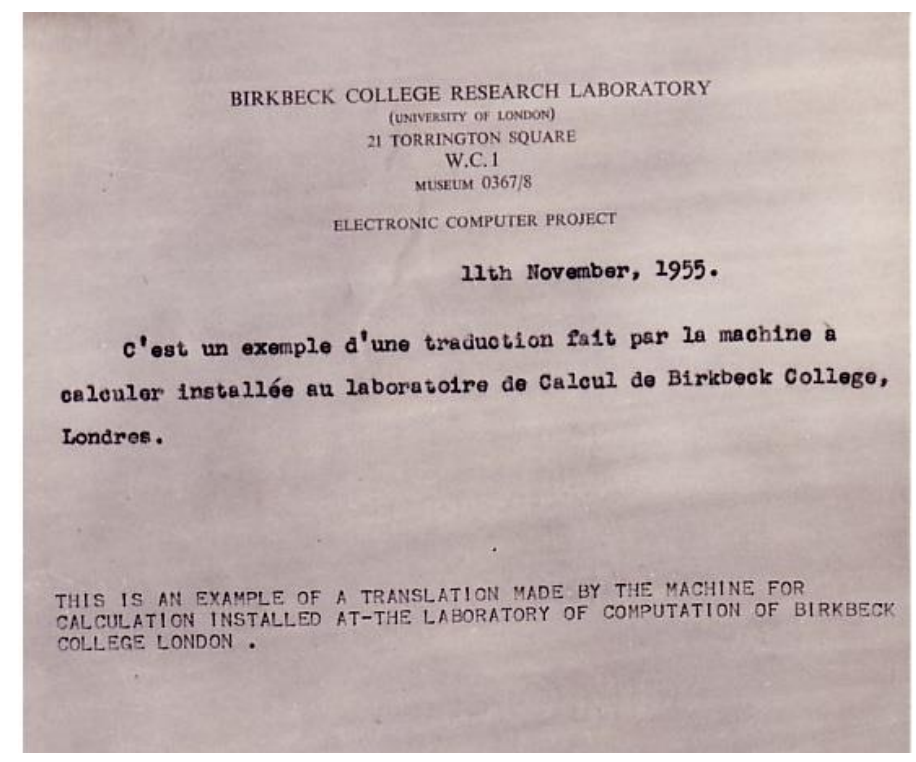

Fig. 8. Output from an early public demonstration of natural language translation 1955

The Booths, with their research students, developed techniques for parsing text and also for building dictionaries. They published numerous books and papers on text processing including creating Braille output and natural language translation. On November $11^{\text {th }} 1955$ the laboratory gave an early public demonstration of natural language machine translation, Fig 8 . Their wider contribution to this community has been assessed by John Hutchins in his paper [7].

\section{Commercial Success}

As noted earlier, the Booths built their computers in a barn at their home in Warwickshire where Andrew Booth's father also lived. So it was to this barn in a freezing March 1951 that a three man team led by Raymond "Dickie" Bird from British Tabulating Machines (BTM) came to visit. BTM were the UK's leading supplier of punch card systems throughout the British Commonwealth and their management had decided that they needed a small computer to improve the calculating power and flexibility offered by their tabulators.

At the time that BTM joined forces with Andrew Booth there were, as described earlier in this paper, three other electronic computer projects in the UK. However, two of the other three, Cambridge and Manchester Universities, already had commercial 
partners while the third, the government National Physical Laboratory (NPL), was not seeking a commercial relationship. Further, Manchester and NPL were building large and expensive scientific computers while Lyons were already building a commercial computer, LEO, with assistance from Cambridge. Consequently, BTM had little option but to cooperate with Andrew Booth.

In just a few days Raymond Bird's team had copied Booth's circuitry from APE(R)C. Returning to BTM's factory at Letchworth they added extra I/O interfaces and named the resulting computer the Hollerith Electronic Computer (HEC), see Figure 9. This prototype computer is one of the world's earliest surviving electronic computers, unlike so many early machines which were dismantled when no longer needed, and is now on display at The National Museum of Computing at Bletchley Park.

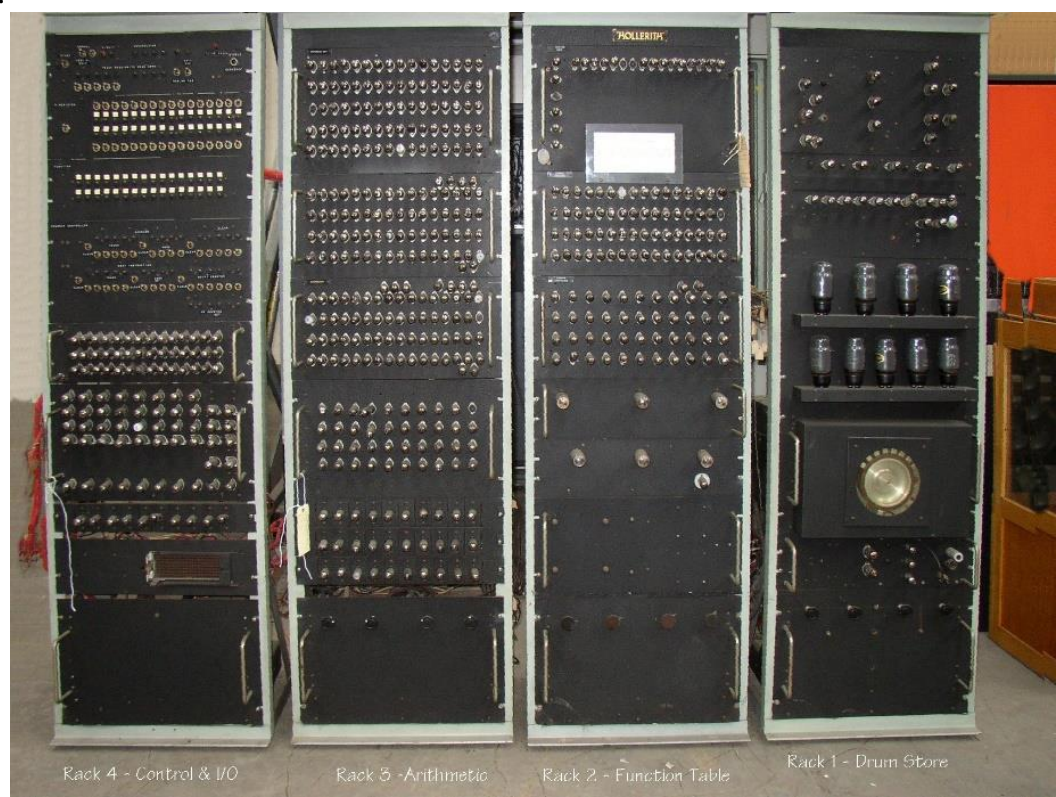

Fig. 9 BTM HEC1 copied Booth's APE(R)C circuits 1951

BTM moved ahead rapidly, completing the construction of HEC1 by the end of 1951 and having it operational later in 1952. BTM management then decreed that the HEC would go to the Business Efficiency Exhibition, the major UK tradeshow, in June 1953 and so a new pre-production prototype (HEC2) was built contained in a smart metal cabinet suitable for demonstration to the public. Two pieces of software were written to attract public interest at the exhibition, one read in 13 out of 52 specially prepared punched cards each representing a different playing card and proposed an opening contract bridge bid while the other played noughts and crosses.

Eight similar machines were built as the HEC2M starting in 1955 mainly for technical applications with a sale price of $£ 25,000$. One of these machines was India’s first electronic computer, [9]. The successor was the HEC4 which was for commercial data processing with nearly 100 being sold in the UK and abroad. At the end of the 1950 s this was the UK's best-selling computer by volume. After BTM merged with 
Powers SAMAS in 1958 to form International Computers \& Tabulators Ltd (ICT) it became the ICT 1200 range. For many companies, and in some cases for whole countries, this was their first electronic computer and opened the door to delivering the wider benefits of effective IT.

\section{End of the Story}

One notable landmark was Kathleen Booth's book on programming the APE(X)C computer, [10]. Published in 1958, this was among the early books on programming and unusual in having a female author. Throughout their partnership, she focussed on the programming while Andrew Booth concentrated on the design of their computers.

Andrew and Kathleen Booth resigned from Birkbeck College at the end of the 1961/62 academic year. Andrew Booth moved to Canada where he continued his distinguished academic career initially at the University of Saskatchewan and subsequently as President of Lakehead University, Ontario. While they continued their research the only machine built in Canada was an updated version of their final British design.

\section{Conclusions}

From the perspective of this conference Andrew and Kathleen Booth were both initially substantial beneficiaries from and then substantial benefactors to the international computing community. The initial support from the Rockefeller Foundation, especially in 1946 and 1947, gave Andrew Booth access to US researchers and John von Neumann, in particular, at a critical time in the development of his ideas for the design and construction of a computer.

He shared his designs with others, notably in the Netherlands and Norway, enabling them to build their own computers. The design of his APEC computers was used to provide the initial design of the highly successful ICT 1200 series computers, primarily used for commercial data processing and which gave access to the benefits to humanity of effective IT for the first time to many places.

The results of Andrew Booth's successful demonstration of connecting a drum to a computer were shared with others in the UK and USA. Although the drum was to be superceded by the disc, the successful use of a magnetic oxide coating for the storage and retrieval of data by a computer was a critical step.

Their contribution to the early work on natural language processing and translation is clear from the review literature. Andrew Booth's initial interest was aroused by Weaver's conversation with him. Much natural language research is by necessity an international collaboration. In this paper there has been time to do little more than note the work of both Andrew and Kathleen Booth on this topic, including their extensive international collaborations.

However, if impact is to be measured by volume, then Andrew Booth's publication of his paper on the Booth multiplier is his major achievement and it remains the basis for multiplication circuits used by chip manufacturers in billions of chips worldwide each year. 
Andrew Booth (1918-2009) is largely unknown outside the specialised world of the computer historian but he, together with his wife Kathleen, deserve far greater recognition by anyone whose computer writes to a hard disk or executes a multiplication instruction.

\section{References}

1. Evans, C. Pioneers of Computing. Audio interview with A D Booth, Pioneers of Computing No 9. Unpublished. Science Museum, London, 1975.

2. Booth, A D. Fourier Technique in X-ray Organic Structure Analysis, Cambridge University Press, 1948.

3. Memo of meeting between Weaver and Booth dated June $20^{\text {th }} 1946$. Rockefeller Foundation Group 1.1, Series 401D, Box 34, Folder 434.

4. Memo of meeting between Weaver and Booth dated July $3^{\text {rd }} 1946$. Rockefeller Foundation Group 1.1, Series 401D, Box 34, Folder 434.

5. Booth A D \& Britten K H V. General Considerations in the Design of an All Purpose Electronic Digital Computer ( $2^{\text {nd }}$ edition), August 1947.

6. Memo of visit by Weaver and Pomerat to ARC dated May $23^{\text {rd }} 1948$. Rockefeller Foundation Group 1.1, Series 401D, Box 34, Folder 434.

7. Hutchins, W J. From first conception to first demonstration: the nascent years of machine translation, 1947-1954, Machine Translation vol 12, 3, 1997, pp195-252

8. Booth, A D. A Signed Binary Multiplication Technique, Quarterly Journal of Mechanical and Applied Mathematics, Vol 4 Pt2, 1951, pp 236-240

9. Rajaraman, V. History of Computing in India (1955-2010). IEEE Computer Society History Committee, 2012.

10. Booth, K H V. Programming for an Automatic Digital Calculator, Butterworth Scientific Publications, 1958. 